\title{
THE PROCESS OF COMMUNITY-BUILDING IN DISTANCE LEARNING CLASSES
}

\author{
Dr. Ruth E. Brown \\ brownr@unk.edu \\ Phone 308-865-8736 \\ Fax 308-865-8806 attn. Ruth Brown \\ Communications Department - Thomas 109 \\ University of Nebraska at Kearney \\ Kearney, NE 68849-1340.
}

\begin{abstract}
The purpose of this study was to develop a theory about the process through which community formed in adult computer-mediated asynchronous distance learning classes. A grounded theory design incorporated archived class input as well as interviews with twenty-one students and three faculty members from three graduate-level distance education classes.
\end{abstract}

A three-stage phenomenon was ascertained. The first stage was making friends on-line with whom students felt comfortable communicating. The second stage was community conferment (acceptance) which occurred when students were part of a long, thoughtful, threaded discussion on a subject of importance after which participants felt both personal satisfaction and kinship. The third stage was camaraderie which was achieved after long-term or intense association with others involving personal communication. Each of these stages involved a greater degree of engagement in both the class and the dialogue.

Causal conditions, intervening conditions, strategies and consequences were enumerated. A visual model of the entire process of community-building was advanced. Benefits of community were noted, and suggestions were made to facilitate the formation of an on-line community.

\section{KEY WORDS}

asynchronous, engagement, learner-centered

\section{INTRODUCTION}

Distance learning is an increasingly important aspect of higher education because it meets the needs of an expanding pool of nontraditional students who find education necessary for jobs in today's information age. Unlike the industrial era when skills needed were relatively fixed, today education is needed to meet employers' growing demand for continually evolving skills. Distance learning provides a convenient, flexible, manageable alternative for this developing segment of society.

However, students in asynchronous distance classes work at computers miles apart at varying times of the day and night. This feeling of being alone is overcome when students join together in a community of learners who support one another [1]. The process of forming a community of learners is an important issue in distance learning because it can affect student satisfaction, retention, and learning [2-5].

The purpose of this study was to develop a theory about the process of community building as experienced by adults in computer-mediated asynchronous distance education classes. More specifically, 
this study sought to ascertain the steps that led to feeling part of an on-line community of learners.

\section{RATIONALE}

Although the term "virtual community" is in common use, few studies have been done to discover how adult distance learning students define community, whether they feel part of a community, and, if so, how that phenomenon occurs. This study is significant because it adds new research, rooted in accepted classroom theory and practice, to the literature for higher education distance learning. This research provides background for curriculum designers and facilitators of distance learning classes, regardless of the field.

In addition, this research has potentially far-reaching implications. One possible implication of distance learning community-building may be students' desire and ability to continue contact with one another and with faculty through electronic networking. Research points to the need for learning communities to sustain themselves $[2,6]$. Yet, at least one study found that interaction stops when a distance learning class ends, just like in a traditional classroom [1]. With the availability of e-mail, this does not have to be the case.

Another implication may be institutional ability to remain in electronic contact with students for alumni, development and community relations activities. The ages and increasing number of nontraditional students make that group ripe for distance learning classes and for friend-raising and fundraising activities that could follow. The technological sophistication of distance learners makes them valuable for electronic networking, grassroots support, lobbying and fundraising.

Therefore, developing theory regarding the process of community-building in college and university adult distance learning courses adds to current literature and provides practical application. If nontraditional distance learners feel a sense of community within the classroom and with the institution, it is possible that this emotional connectedness may provide the support needed for them not only to successfully complete a class or a program but also to have a positive lifelong affiliation with both the department and the degree-granting institution $[7,8]$.

\section{METHOD}

\section{A. Research Questions}

The research was guided by the following central question:

How was community formed in an adult computer-mediated distance learning class?

Sub-questions were as follows:

How did participants describe or explain community?

What were the actions or events that led to community?

What was the process of forming a community in a computer-mediated class?

What phenomenon was at the center of the process?

What caused the phenomenon?

What was the extent of community-building? 
What were the intervening conditions and contexts that affected community-building?

What strategies were used in the community-building process?

What was the theory regarding the process of community-building?

\section{B. Definitions}

For the purpose of the study, the following definitions were used initially. As the study progressed, participants provided their own definitions of community.

Community meant, "support from people who share common joys and trials" [9].

Community-building referred to creating a sense of belonging, of continuity, of being connected to others and to ideas and values [10].

Community of learners meant a group of people with "a shared purpose, good communication, and a climate with justice, discipline, caring, and occasions for celebration" [11].

A distance learner was "anyone who is not actually in the presence of the teacher while learning, whether in a study room, in the next building, at home or in a place located hundreds, even thousands, of miles away" [12].

\section{Research Design}

\section{Qualitative}

The qualitative paradigm was chosen for this study for reasons which parallel assumptions made by Merriam [13] regarding qualitative research. Merriam said "qualitative researchers are concerned primarily with process, rather than outcomes or products," [13] and this study was concerned with the process of community-building in a distance education class. It produced an understanding based on multiple contextual factors, but is not meant to generalize [14].

\section{Grounded theory}

Grounded theory was the qualitative design chosen for this study because, unlike many other forms, it uses a "systematic set of procedures to develop an inductively derived grounded theory about a phenomenon" [15]. The purpose of a grounded theory study is to build theory that is both faithful to and illuminates the area of study. In this study, the findings converged to explain the process of forming a community in a distance learning class. The grounded theory methodology generated, and to some degree provisionally tested, the concepts and the relationships between and among them.

\section{Data Collection Procedures}

\section{Site Selection}

The first level of purposeful sampling was site selection. Chosen were graduate level educational administration courses delivered asynchronously from a midwestern university by Lotus Notes through the Internet. The technology provided multiple mechanisms for interaction between and among students and faculty, as well as archiving capabilities. The software included areas for large group work, small group work, a "library" for inputting relevant literature and commenting on it, a "cafeteria" for casual "conversation" and a "faculty office" for questions and answers. The Lotus Notes classes were created to 
emulate a learning organization, touted by Senge [16], which employs systems thinking, personal mastery, mental models, team learning, and shared vision.

\section{Participants}

The second level of purposeful sampling involved selecting the participants. Research participants were selected according to their ability to contribute to the evolving theory. Miles and Huberman [17] called this theoretical sampling. This begins with selecting and studying a homogeneous sample of individuals and then, after developing the theory, selecting and studying a more heterogeneous sample to confirm or disconfirm the contextual and intervening conditions under which the model appears to hold true.

All twelve students in a fall semester class (henceforth referred to as "the veteran class") participated. Veterans were selected because earlier research indicated that computer-mediated distance learners progress through stages from novice to experienced learners [18]. Other factors used to select students for the study were the frequency and supportiveness of their archived class input because supportive interaction has been shown to be an important factor in community [9] as well as in computer-mediated classes [18]. Constructive criticism and encouraging comments are examples of communication that is considered supportive.

Six students were chosen from a spring semester class that contained many new distance learners. (This class will be referred to as the "newbie" class.) These students were chosen to test the concepts being constructed and to see if new ones emerged. Three students were chosen from a five-week summer class (henceforth referred to as "the summer class") which contained both veterans and newbies, again to test the concepts. The two faculty members who facilitated these classes were also chosen to participate. The third faculty member chosen was instrumental in starting the program and continued to facilitate classes. During study of the summer class, theoretical saturation was reached.

It should be noted that when the word "students" is used in this study, it refers to the twenty-one distance learning graduate students. When the word "participants" is used, it refers to these twenty-one students plus the three distance learning faculty members.

\section{Types of data}

In grounded theory, most of the data comes from interviews with the participants [19]. The first round of interviewing was done by telephone in order to establish similar rapport with participants who were both near to and far from the researcher. Following the interview, the researcher recorded impressions, "observations," reflections and interpretations in a computer diary. The second round of questions was directed by the data that emerged from the first round and was accomplished by e-mail. In those cases where follow-up questions were needed for either the telephone or the e-mail interviews, the questions were sent and responded to by e-mail. In addition to interviews, participants' archived Lotus Notes input was studied.

\section{E. Data Analysis Procedures}

Grounded theory uses set procedures for analysis of the data. These are coding procedures, devised by Strauss and Corbin [15], which involve breaking down the data, conceptualizing it, and putting it back together in new ways. This is the "central process by which theories are built from data" [15]. Open coding, axial coding and selective coding are all used to analyze the data. Open coding develops categories of information, axial coding connects the categories, and selective coding creates a story or 
visual model that connects the coding and categories. The final result is a set of theoretical propositions, which are then provisionally tested.

Nine themes or categories emerged through open coding that characterized community-building in asynchronous text-based distance education graduate classes. These categories were "similarities/ differences" of students, their various "needs," the "student's role," the "instructor's role," the "class structure," the "program structure," participants" "comparisons" of various forms of distance education as well as comparisons of distance and face-to-face classes, past and future "change" in communities and in education, and "feelings" they experienced during their distance learning classes.

Relationships between categories were explored through axial coding. A paradigm model was developed that portrayed the interrelationships of the axial coding categories by using the following headings: causal conditions, phenomenon, context, intervening conditions, strategies and consequences. (See Figure 1.) From this, selective coding generated a theory which is shown here as a visual model with accompanying explanation. (See Figure 4.)

\section{F. Methods for Verification}

The following strategies, common to qualitative research [19], were used to ensure internal validity: longterm observation at the research site, triangulation of multiple data sources, member checks, peer review, and rich, thick description.

\section{RESULTS}

\section{A. Community Defined by Participants}

Two themes emerged from the participants' descriptions of community. The first was that members of a community generally had something in common, whether it was interests, experiences, goals, values or vision. Many participants seemed to say that commonality was the essence of community. The second theme was derived from participants' descriptions of "learning community." Those definitions seemed to involve more action on the part of participants who said they were responsible in part not just for their own learning but for others' learning, too. That pointed to interaction as a potential core category because it was through interaction that similarities were found and that thoughts and feelings were exchanged.

Participants' definitions of community often were a predictor of whether or not they felt part of a community. Two students felt that face-to-face association was necessary for community, and two felt that people needed to come together voluntarily to be part of a community. This foretold what they later stated, that they did not feel a sense of community in their on-line classes.

\section{B. Community-building Paradigm}

The paradigm created by axial coding elicited additional results of interest. It noted the context in which community formed, the conditions needed for the formation of an on-line community, intervening conditions, which can positively or negatively affect its formation, and strategies for overcoming negative conditions and utilizing positive conditions. The paradigm also first identified the three-stage phenomenon of community. It also enumerated the many beneficial consequences. It is best summarized in the following figure. 
Figure 1. The Community-building Paradigm

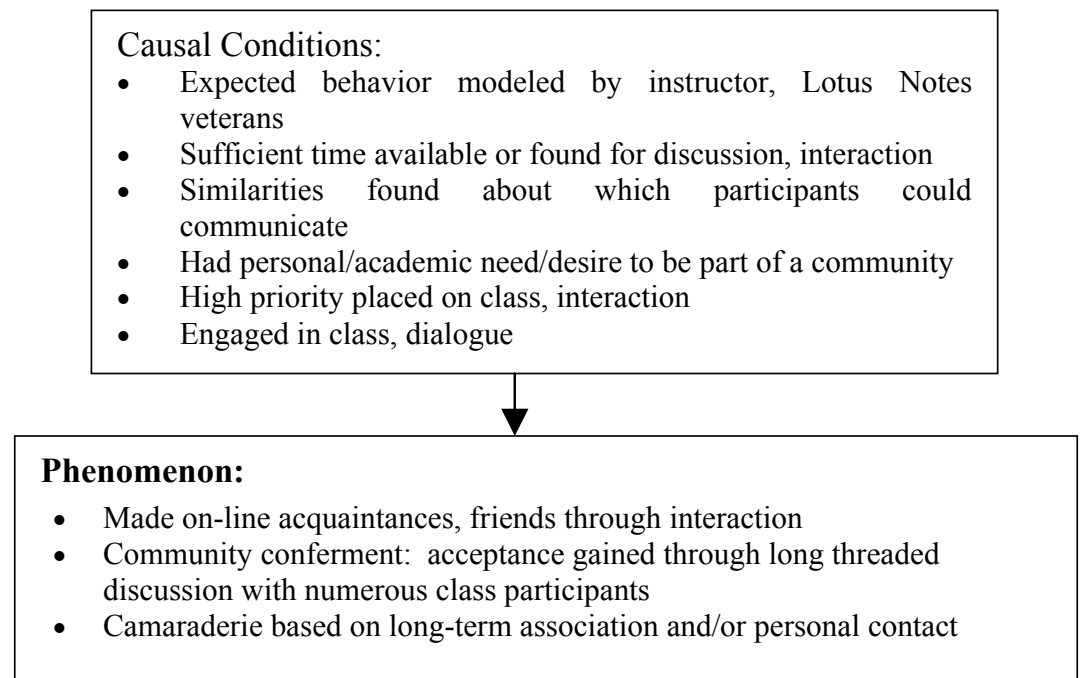

Context:

- EdAd classes with non-traditional students who generally sought Ph.D. for career advancement

- Computer-mediated asynchronous Lotus Notes Classroom with multiple paths for textual interaction

- $\quad$ Satisfactory support services provided by department, university

- Collaborative, self-directed learning used to facilitate active participation

- Participants in various geographic locations connected by common interest or goal
Intervening conditions:

- Students from various backgrounds, locations

- Varied motivation, expectations, commitment, needs

- Varying abilities with technology, typing, writing

- Computers, internet of varying speeds, capabilities

- Size of class and/or work group

- Length of term (semester or summer session)

- Delayed receipt of textbooks, software, and/or software problems

- Health of self, family members

- Time available or found to devote to class

- Time required to feel comfortable with software, teaching method, class content, faceless interaction with participants

- Decision how much to participate and with whom

- Personalities and how they manifest themselves on-line

- Students' learning styles and instructors' teaching styles

- Amount, substantiveness, timeliness of feedback

- Different definitions of community, learning community

Strategies:

- Created class atmosphere that promoted openness, respect, trust

- Demonstrated interest, support, sincerity, understanding

- Shared relevant experiences as well as information that would help others

- Worded responses positively, even when challenging ideas, information

- Communicated in the cafeteria as well as in the classroom

- Provided timely feedback

- Reached out for help when needed

- Responded quickly when someone reached out for help

- Grappled with issues, problems together

- Tried to get threaded discussions going or keep them going

- Communicated with individuals personally outside of Lotus Notes 


\section{Consequences:}

- Participant gained confidence in ability to express self, debate with intelligent people

- Participant learned from and about others in class; others learned from and about him/her

- Participant felt connected to class members despite their being "faceless"

- Participant felt like a valued, contributing member of the classroom community

- Participant felt accepted into the community and worthy of membership

- Participant passed on feelings of validation and acceptance to others

- Participant felt a genuine sense of belonging to classroom community

- Participant made lifelong friends with whom he/she could easily communicate

- Participant felt connected to the department and to the university through positive experiences

\section{Three Levels of Community}

Three levels of community were identified. The first was making on-line acquaintances or friends. (Some students considered them friends. Others didn't.) Students said they found people on-line toward whom they gravitated. Often these were people with whom similarities were found. Sometimes the similarities were in location or academic background. Sometimes they were in commitment or motivation. Sometimes they were similarities in circumstances. Regardless, students who found similarities began interacting on a regular basis. This might, in fact, be the level at which most researchers seeking community stopped because the communication between these friends or acquaintances was recurrent. This recurrent communication, however, was due at least in part to the class requirement for students to react to other students' academic input.

It was the next level, community conferment that many students pointed to as being like a membership card for the community of learners. What gained them membership into the community was being part of a long, thoughtful, threaded discussion on a subject of importance to all. Inclusion in this discussion was important to students because the ideas they offered were accepted by others and were considered worthy of further discussion. At the conclusion of the discussion, they felt personal satisfaction in their own knowledge and ability to communicate. They also felt a kinship with those who had participated -- like they really were part of a community.

The third level was camaraderie which was achieved after long-term and/or intense association with others involving personal communication. This was the highest level of community and generally was found among those students who had been through multiple classes together, had communicated outside of Lotus Notes (usually by telephone or e-mail) and, sometimes, had met each other at a summer session on campus.

Each of these levels of community involved a greater degree of engagement (Figure 2) in the class, as noted in interviews, and, particularly, in the dialogue, which was evidenced in archived input. Those who felt connected placed a high priority on the class and allotted time accordingly, desired to get to know others and learn from them, were highly motivated, participated frequently in a timely fashion and demonstrated respect for all participants. Thus, increased levels of community accompanied increased participation/ engagement in the class and vice versa. 
Figure 2. Conditional Matrix

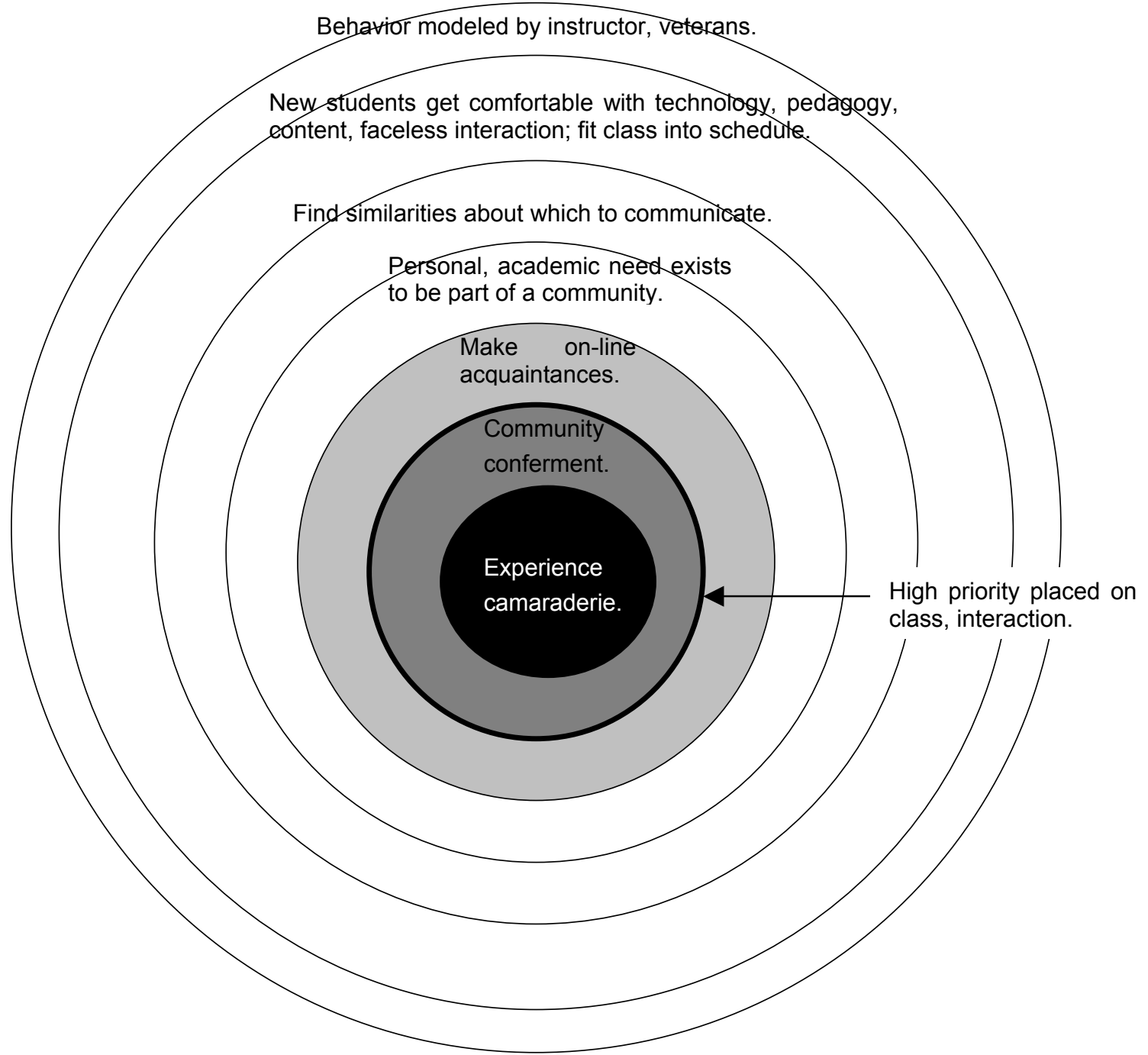

Darker shades of gray indicate higher levels of

1) Engagement in class and dialogue

2) Feelings of belonging to a community

\section{No Community}

Even though this researcher identified three levels of community, five of the study participants said they felt no sense of community in on-line classes, and four were inconclusive in their answers to the question. How was this possible? The following explanations were found: 
1. The participant did not even think about community prior to or during enrollment in the class. He or she was enrolled purely for the knowledge or for the credits.

2. The participant did not want to be part of the community -- did not want to bother with positive, supportive messages and interaction in the cafeteria. Knowing this interaction would not be considered when the grade was determined, the participant did the required work but nothing more.

3. The participant was "out of synch." He or she had health problems, family members with health problems, an overload at work, technology trouble, or other circumstances that prevented him or her from full engagement in the class.

4. As mentioned earlier, a few students' definitions of community did not permit community to be found on-line either because they felt interaction needed to be face-to-face or because they felt communities should be voluntarily assembled. Interestingly, though, it was the voluntary associations with each other on-line (such as in the cafeteria or by e-mail) or by phone or Fax, which went beyond the requirements that created community for many participants.

5. A few people simply did not prioritize the class at a level that would have required more time and devotion. These students usually found people on-line with whom to regularly respond but didn't necessarily develop a "relationship" beyond the practical one. These were generally the students "on the fringe." They talked about community as if they saw it on-line, perhaps even wanted to be part of it, but could not afford the time or would not devote the time necessary.

\section{E. Time Triangles}

This situation exemplified another portion of the theory, which is referred to here as the Time Triangles (Figure 3). Students new to Lotus Notes had to spend a large portion of their first few weeks getting comfortable with the technology, understanding the learner-centered teaching method, and familiarizing themselves with the class content. They were unprepared for the amount of time required for this, so they had to juggle jobs, family and activities to fit in this new addition to their schedule. Picture a triangle that represents time. The base of that triangle represents the time needed by these students to get up to speed on the technology, pedagogy and content. The peak is the time that is left for students to get to know each other and to participate in community-building activities.

Figure 3. Time Triangles

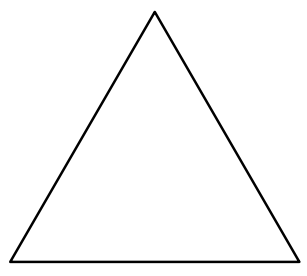

New Students
Community-building

Course content

Teaching method

Technology

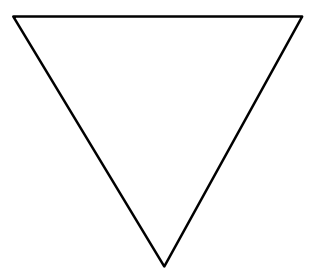

Veteran Students

Now picture an inverted triangle that represents time for the veteran Lotus Notes user beginning another class. The peak at the bottom represents the amount of time needed to become familiar with technology (which is the same as previous classes) and pedagogy (which is similar). The large base at the top represents the time veterans have available for class content and for community-building activities. 
Nearly all the students in all the classes studied wanted more input from professors, but, as noted by the professors, computer-mediated distance learning was an extremely time-consuming task for them as well as for students. New students needed more support and encouragement sooner than veteran students because of the anxieties they experienced relative to the technology, pedagogy, and doctoral level class content. Veterans may have wanted this interaction, but their need for it was less since they had succeeded in "mastering the process" [18] and completing Lotus Notes classes.

New students tended to want a tight class structure (shorter assignments and shorter deadlines) with frequent interaction (particularly encouragement) and helpful assessment (especially validation) from the instructor at the beginning. They suggested assignments that would help them get to know each other, discuss expectations, determine individual goals and that would promote sharing life experiences and professional experiences sooner. All this was less important to veteran students.

Veteran students were able to jump right into the class and begin modeling the expected behavior, supporting and encouraging peers, sharing their knowledge and experiences, reflecting on past learning, applying the content and quickly becoming engaged in the class. As new students gained experience and confidence, they began to take on some of these added responsibilities.

Veterans were able to continue friendships and/or acquaintances begun in earlier classes. They knew previous classmates' views on issues and could continue discussions begun earlier, so community redeveloped quickly among them. When new students jumped into these conversations, they were generally accepted, and when veterans reached out to new students, they joined in faster. However, if conversations among veterans appeared closed or if veterans did not reach out to new students, this slowed the overall community-building process.

\section{E. The Process of Community-building}

This researcher took all of the data from open and axial coding and looked at it in reference to change and to interrelationships which is what produced the process of community- building in distance learning classes. (See Figure 4.) Steps involved in building a community in computer-mediated asynchronous classes are as follows:

1. Tools. Students received textbooks and software for class, successfully loading software so that they could start the class on time, "in synch". They successfully sent the first message. (Replicating and receiving the first response was a big step. Many people pointed with relief to getting that first message out and a response back. This success allayed some of the anxiety.) Thus, the tools began to link the geographically separated individuals so that they could come together as a community.

2. Comfort level. Students gained confidence with the technology, the teaching method and style, as well as the content. Also, they began fitting the class into their personal schedules (developing a pattern of participation) and learning to function in a faceless interactive environment. This involved learning to think and write at the keyboard, learning the level (quality) of work expected, learning how to operate in and what to expect from a collaborative/ self-directed learning virtual class, learning the ins and outs of the technology, devising strategies for overcoming problems with it as well as strategies for managing time, and dealing with class content.

Achieving a satisfactory comfort level was a huge step. Some called it a "double whammy" involving technology and content, but it was really a triple whammy because it was often the first time they had 
participated in a collaborative/ self-directed learning environment. This was a real muddling-out step, one where the veterans had the advantage. The new students were overwhelmed at this point, especially if they were late to log on or get textbooks. Support from the professor and from peers was essential here. One of the problems was that Lotus Notes veterans were able to move rapidly through this stage, but new students were overwhelmed by it. If new students didn't reach out to others, they could easily feel alone.

3. Self-assessment and judgments. Because new students didn't know there were veterans in the class, they had self-doubt, questioning why they seemed to have difficulty while others did not. Ability to perform at the doctoral level was questioned by new students because this was a Ph.D. program, they hadn't been in class for a long time, they weren't good writers, typists or whatever. The new students did some self-assessment, reading what others had input and reading the responses others had received, as the new students attempted to raise their own comfort level and self-confidence. It was at this stage that some students said they found they needed to shed their shyness and/or their fear of showing ignorance and hunker down. It was at this stage they said that dropout could occur, particularly if the student had not moved through the first two steps in a timely fashion.

Figure 4. The Process

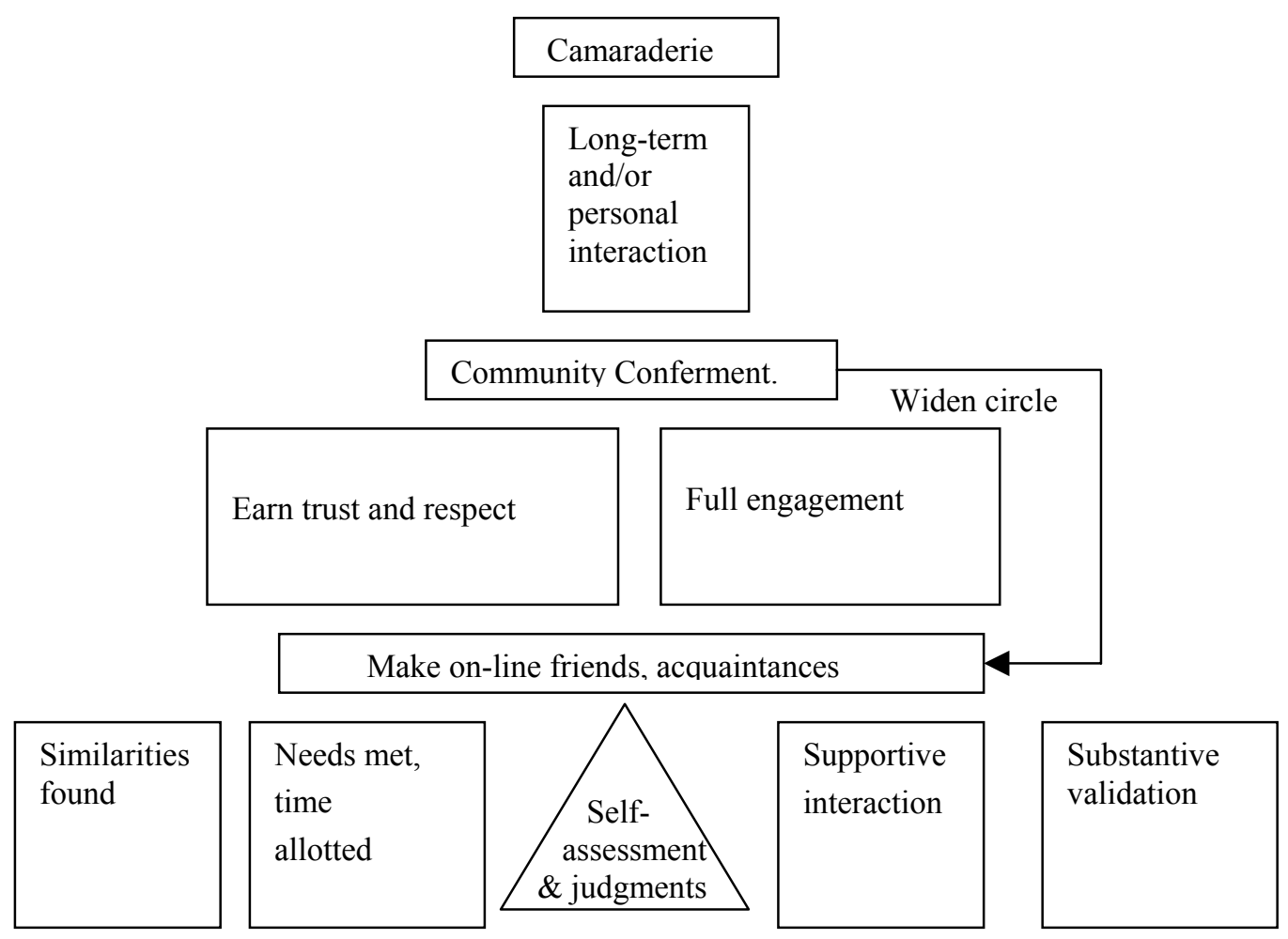

As students read others' input, they made conscious or unconscious judgments about each other based on the style, content and/or timeliness of the written messages. Students judged others' intellectual caliber according to the knowledge and understanding shown in the input. If students input their messages just before deadline, others thought it showed that they didn't place a high priority on the class. Writing styles and on-line personalities were also factors used to "judge" each other. Most participants agreed that personalities tended to "bubble out" -- sooner for those with stronger virtual personalities. It was at this stage that decisions were made as to how much and with whom to participate. 
Veterans often gave initial greetings to new students, but were more apt to interact with each other because they knew each other's viewpoints, writing styles and even dedication. New students didn't know with whom to interact at first.

4. Similarities. As students read each other's input and read about each other in the class roster, they began to find classmates with similar backgrounds, interests, ideas or shared circumstances. Students used those similarities to begin virtual conversations. Those who were administrators began reacting to one another's input, as did those who were from community colleges, and so forth. The summer class was composed primarily of women who were full-time educators as well as wives and mothers. Some had young children, and some were grandmothers, but their circumstances were similar enough that they easily found common ground about which to converse on-line.

5. Needs met. Once students were comfortable with faceless interaction, they consciously or unconsciously determined whether interaction with others (beyond that which was required) met any of their personal or academic needs or desires. Some students enjoyed the networking, some just liked chatting in the virtual cafeteria, and some needed help with the technology or the subject matter. Those were cases where interaction beyond that required met the students' needs.

6. Time allotted. Students decided on their level of commitment and allotted their time accordingly. If this class met their personal or academic needs, they tended to allot more time to it. If it met academic needs but not personal needs or vice versa, that was reflected in the time they allotted to it. Competing considerations were family- and job-related obligations. Students who enjoyed or preferred written communication seemed to have no difficulty transitioning to the Lotus Notes classes and didn't mind the extra time required for the written communication. Those who enjoyed or preferred oral communication such as that found in face-to-face classes had more difficulty with the transition because they became frustrated with the amount of time needed to input messages and with the time delays necessary for responses.

7. Supportive interaction. Community-minded participants were interested in and provided positive reactions to each other's cafeteria and classroom input. Receiving such messages bolstered participants' self-confidence and raised their comfort level.

8. Substantive validation. Participants received substantive validation (not just "good job") from participants in their virtual classrooms, showing that the students' ideas and opinions were valued and respected. This was important. The student had to feel that his/her ideas were worthy of discussion.

9. Acquaintances/friends. Participants found persons toward whom they gravitated on a regular basis. Often this was because of similarities in motivation, dedication, academic or personal background. Regardless, these were people they felt comfortable interacting with and who they thought would help them when needed.

10. Earning trust, respect. Earning each other's trust and respect was a continuing effort that anchored a virtual friendship or even an acquaintance in the classroom community. This involved students continually demonstrating both their ability and their reliability: they consistently interacted positively with well-written, knowledgeable, timely, supportive input. 
11. Engagement. The student became fully engaged in both the class and the dialogue, as evidenced by input in the virtual classroom, small group work areas, and in the cafeteria.

12. Community conferment. The student either started or was part of a long threaded discussion, generally in the classroom. This demonstrated his/her full engagement in the class. It made the student feel part of a bigger whole, part of a classroom community that together was examining or struggling with information, an issue, or an idea. This was acceptance; it was the membership card.

13. Widen circle. Once students gained acceptance through threaded discussion they interacted more confidently with others, often even widening their circle of acquaintances or friends and receiving more validation which bolstered their self-confidence so that they could then help bring others into the community. (One could see how veterans played a major role, conferring community on new students.)

14. Long term/personal communication. Communicating outside of Lotus Notes brought a virtual classmate into more tangible reality and helped form or strengthen a relationship with that person or persons. Various intensities existed from e-mails to phone calls to actual meetings. A first step often was a personal e-mail which one participant described as being more like "inviting a classmate home". Faxing material was more personal than communicating to an entire group in Lotus Notes. Phone calls elicited vocal intonations that helped communicate humor and emotions. Of course, face-to-face meetings probably did the most to help cement relationships begun in virtual classrooms. Long-term association in Lotus Notes and/or communication outside of Lotus Notes helped participants develop an even stronger bond.

15. Camaraderie. Although veterans were actively involved in the conferring of community to others, there was still one more step for them to take, one more level for them to achieve. That was achieving a feeling of camaraderie. This usually occurred after long-term and/or intense association with participants, and/or positive face-to-face interaction that followed on-line associations. It occurred almost unnoticed, less a result of particular actions or events, and more a result of an accumulation of actions and events.

The above steps did not necessarily all occur in this order for everyone, but they provide a framework for understanding the process of community-building in computer-mediated distance learning classes. Following is a factor noted by most participants that aided in the process of community-building. It is offered separately by this researcher because it occurred at different times for different participants in different classes, depending on how the classes were structured and depending on the involvement and leadership of the participants.

Getting to "know" each other. Finding out where people lived, what they did, their experiences, whether or not they had families and the like was the "X" factor. Participants generally agreed that this should have been a first step in community-building, but usually it was not part of the formal coursework. Students usually got to know each other by gathering information from the roster and adding to it piece by piece from responses. That took time. One professor asked students to write about themselves for their first assignment. However, most professors launched right into the course content.

Regardless, some students made an effort to get to know each other early because they said it helped them interact. They looked at the roster often or printed it out and referred to it so they could respond to "real" people, not just text. Many members of the summer class used the virtual cafeteria to tell about 
themselves, even though they were not required to do so. These were students who had a need for community and who took the time to help it form.

\section{F. Propositions}

Using the process as a guide for analysis, the categories were again rearranged in order to generate the following theoretical propositions that were grounded in the data.

1. Community did not happen unless the participants wanted it to happen. That observation referred back to similarities and differences in participants' personal and academic needs. If the participants needed or wanted community for whatever reason, they were apt to find it. Some saw it as an opportunity to network. Some just naturally wanted to participate and, in fact, provided some of the glue that was needed to put a community together and keep it together. Some participants were resistant to membership in a community so they purposely did not get involved or stayed on the fringes.

2. On-line community was present for some participants and not for others, even though they were in the same class and even though that class was described by numerous students as having a lot of community. This researcher purposely chose a particular student for inclusion in the study to test that notion. This was a student who was in the summer class that also was chosen specifically because participants pointed to it as having a lot of community. The student didn't have a lot in common with other participants and didn't interact in the virtual cafeteria. He was comfortable with the technology, pedagogy and content, but preferred face-to-face (or at least oral) communication.

3. Modeling, encouragement, and participation by the instructor helped community form more readily for more students in computer-mediated classes. The most obvious example of this was offered by a student who was in two summer classes, one of which she said had a lot of community and one of which had only a little. The one with a lot of community had three times the number of students, but the faculty member took an active role, responding 180 times in the faculty office, compared to nine responses by the faculty member in the smaller class with only a little community. Now the 180 faculty office responses constituted an unusually high number compared to responses input in a semester-long class. Nonetheless it dramatized the third insight.

4. Participants had to get comfortable with the technology used to deliver the classes, with the doctoral level class content, with the collaborative learner-centered teaching method, and with faceless interaction before they could become active members of a classroom community.

5. Veteran students could help create on-line community or hinder its formation or both. New students needed veterans' support and encouragement to continue as they "learned the ropes." Veterans often helped create community by modeling expected behavior, but that was generally in the early days of class. After the initial sign-on interaction, veterans often went back to communicating with "friends" from previous classes, which hindered the overall formation of community. More community-minded veterans with outgoing virtual personalities generally widened their circles of friends/ acquaintances, which facilitated the formation of community.

6. Community could be experienced at any of three different levels: having on-line friends or acquaintances with whom participants interacted regularly, feeling part of an on-line classroom community, and enjoying camaraderie. 
7. Membership in the on-line community was conferred by others through feelings of worthiness and acceptance or belonging that occurred following participation in long threaded discussions.

8. Voluntarily interacting beyond class requirements promoted the feeling of community in computermediated classes. Whether this interaction was in the form of additional classroom input, virtual cafeteria input, individual e-mails, phone calls, faxed material, or face-to-face meetings, the cumulative effect was that the person creating the additional interaction was more fully engaged in the class and so found more community there.

9. Levels of community experienced were closely linked to levels of engagement in the class and dialogue.

10. Long-term association with each other helped promote on-line community because students who went through multiple classes together could continue to amplify on-line relationships so that a higher level of community resulted over an extended period of time.

11. Qualities such as respect and trust were found in descriptions of on-line classroom community members even though such feelings had to be transmitted through text only on a computer screen.

12. Feelings of acceptance and worthiness were transmitted through on-line community conferment, but on-line acceptance and worthiness were more likely to be based on the quality of the participant's input than on his or her virtual personality.

\section{DISCUSSION}

\section{A. Insights}

This researcher could find no specific amount of time necessary before a new student considered himself or herself a veteran student. In telephone conversations, a few students who had successfully completed several classes admitted to still feeling like new students. This was more obvious in the second round of questions when participants were asked to tell when and how they became comfortable with technology, pedagogy, class content and classmates. Some, who were well into their distributed doctorate programs, had only recently become comfortable with certain aspects of the class, and a few admitted still not being comfortable with certain aspects even though they were nearly finished with their programs. These were generally the same students who did not find community or who were on the fringe of community. On the other hand, a few students transitioned rapidly to achieve a satisfactory comfort level in all areas after only one class -- sometimes, after just a few weeks. These were students who also found community. Thus, the veteran status appeared to be an individual phenomenon based on personality, time, interaction and perhaps the intensity of the class -- certainly on participation and engagement. Additional research is needed to clarify this.

Students utilizing computer-mediated communication said they generally took a longer period of time to create bonds of friendship, community or camaraderie than they might have in face-to-face associations, but the necessary elements were present for those who wanted to utilize them. Physical appearance, mannerisms, and voices were not factors in determining on-line friends or community members. Rather, judgments were based on textual input, particularly content. Other factors were timeliness and 
supportiveness of input, as well as virtual personality, perceived intelligence, commitment, and writing ability of the participant.

Several participants talked about how they witnessed students "gathering around" the person who reached out and shared his or her problems, providing support and encouragement, which helped the recipient feel as though the problem was surmountable so that membership in the class or program could be continued. Several students said they could "see" students on the fringe and suggested that it might be possible to nudge them into greater participation and/or more timely participation that would help them find community more readily. Satisfied students served as ambassadors for the program, recruiting others in their institutions to enroll. More research is needed to determine if community can help deter dropout and to see how closely community and satisfaction correlate, but those in this study who said they found community also expressed satisfaction with the classes.

How does an instructor create a desire to participate, to become a community member? Students suggested that foregrounding them would help. Have a discussion of on-line community immediately upon login. What is on-line community? How is it achieved? That's what this study sought to find out. What can participants expect to gain from it? Some students don't realize that it is an opportunity to learn from each other, to network with each other, and to gain support (help beyond what the instructor can provide). Early discussion of community and its potential benefits may create a perceived need that students will then want to fill. Certainly the discussion will convey that community is a course expectation so students will work to meet it.

Build in an opportunity for the students to learn more about each other to facilitate early discovery of commonalities. In addition, ask the students to provide e-mail addresses, phone numbers (suggested but not required) and FAX numbers to encourage communication beyond the required responses. Ask them to note in the cafeteria when they are planning to go to what conferences or to be on-site because others from class may be there, and they could meet face-to-face.

Consider using a community reflection piece, perhaps three times a semester, in which students note what they have done to contribute to community, what others have done to help them feel more a part of a community, what this has accomplished, and what still needs to be attained. This assignment will remind students that a community of learners can be created on-line, is deemed important by the instructor, and can benefit them both now and in the future.

If instructors and curriculum designers realize how community is built on-line and if students understand the benefits of community and are given the background, tools and expectation for community, then it should happen more readily.

\section{B. Implications}

The great potential that learner-centered computer-mediated classes have is that when a community forms, its members can easily keep in contact with one another through the very medium they used to create the community, the Internet. Community does not have to end when the class or the program ends. The department or institution should consider ways in which to continue two-way communication that facilitates community. The department or institution can readily keep in contact with the students through a database of e-mail addresses, a listserv, or a web site. Thus, a community formed through the classes and the program, can be maintained not only for the students' benefit (which might be personal, academic or both) but also for departmental and university purposes such as fundraising and networking. 
Community-building should be emphasized not just for the sense of togetherness it provides students, but also to help keep the students in the class and in the program, to promote full engagement in the class, to facilitate effective collaborative learning, and to encourage continued communication after the course or program is complete for development and career services purposes.

\section{REFERENCES}

1. Eastmond, D. V. Alone but together: Adult distance study through computer conferencing. Cresskill, NJ: Hampton Press, Inc., 1995.

2. Gabelnick, F., Mac Gregor, J., Matthews, R. S., \& Smith, B. L. .Students in learning communities: Engaging with self, others, and the college community. New Directions for Teaching and Learning, Vol. 41, pp. 39-51, 1990.

3. Kember, D. A longitudinal process model of drop out from distance education. The Journal of Higher Education, Vol. 60, No. 3, pp. 278-301, 1987.

4. Kowch, E., \& Schwier, R. Building learning communities with technology. Paper presented at the Second National Congress on Rural Education, Saskatoon, Saskatchewan. ERIC Document Reproduction Service No. ED 405 857, 1997.

5. Powers, S. M., \& Mitchell, J. Student perceptions and performance in a virtual classroom environment. Paper presented at the Annual Meeting of the American Educational Research Association, Chicago, IL. ERIC Document Reproduction Service No. ED 409 005, 1997.

6. Herrmann, F. Listserver communication: The discourse of community-building. http://wwwcsc/95.indiana.edu/csc/95/herrmann.html

7. Hallett, J. Build relationships; then raise money. Philanthropy Journal. http://www.philanthropyjournal.org/tech/hallett2797.htm

8. Tobin, K. The language of request: Annual giftgiving to the university. Paper presented to the Association for the Study of Higher Education, Washington, DC ERIC Document Reproduction Service No. 232 546, 1983.

9. Dede, C. J. The evolution of distance education: Emerging technologies and distributed learning. American Journal of Distance Education, Vol. 10, No. 2, pp. 4-36, 1996

10. Sergiovanni, T. J. Building community in schools. San Francisco: Jossey-Bass, 1994.

11. Boyer, E. The basic school: A community for learning. (2nd printing) Ewing, NJ: California Princeton Fulfillment Services, 1995.

12. Duguet, P. Education: face-to-face or distance? OECD (Organisation for Economic Co-operation and Development) Observer, 194 , pp. 17-20, 1995.

13. Merriam, S. B. Case study research in education: A qualitative approach. San Francisco: JosseyBass, 1988

14. Creswell, J. W. Research Design: Qualitative and Quantitative Approaches. Thousand Oaks, CA: Sage, 1998.

15. Strauss, A. \& Corbin, J. Basics of qualitative research: Grounded theory procedures and techniques. Newbury Park, CA: Sage, 1990.

16. Senge, P. M. The fifth discipline: The art and practice of the learning organization. New York: Doubleday, 1990.

17. Miles, M. B., \& Huberman, A. M. Qualitative data analysis: A sourcebook of new methods (2nd ed.). Thousand Oaks, CA: Sage, 1994.

18. Scott-Fredericks, G. The graduate student experience in computer-mediated classes: A grounded theory. Unpublished doctoral dissertation, University of Nebraska, Lincoln, 1997.

19. Creswell, J. W. Qualitative inquiry and research design: Choosing among five traditions. Thousand Oaks, CA: Sage, 1998. 


\section{ABOUT THE AUTHOR}

Dr. Ruth Brown is an assistant professor in the Communications Department at the University of Nebraska at Kearney. She made a presentation on "Building Community On-line" to the 2001 American Association of Higher Education Conference on Faculty Roles and Rewards, on "Community as an Online Teaching Tool" to the 2001 Nebraska Faculty College, and on "The Process of Community-building" to a symposium of Educational Administration graduate students at the University of Nebraska - Lincoln. 